\title{
Surfactant-assisted Hydrothermal Synthesis of Ceria-Zirconia Nanostructured Materials for Catalytic Applications
}

\author{
Cimi A Daniel, S.Sugunan \\ Department of Applied Chemistry, Cochin University of Science and Technology Cochin-682022, Kerala, India.
}

\begin{abstract}
CeO}_{2}-\mathrm{ZrO}_{2}$ oxides were prepared by the surfactant-templated method using cetyl trimethyl ammonium bromide $(C T A B)$ as template and modified with chromium nitrate. These were characterized by $X R D, F T-I R, T E M, S E M, B E T$ and TPD-CO $\mathrm{C}_{2}$. The XRD data showed that as prepared $\mathrm{CeO}_{2}-\mathrm{ZrO}_{2}$ powder particles have single phase cubic fluorite structure. HRTEM shows mesoscopic ordering. Average particle size is 12-13 nm as calculated from particle histogram. The nitrogen adsorption/desorption isotherm were classified to be type IV isotherm, typical of mesoporous material. The presence of uni-modal mesopores are confirmed by the pore size distribution which shows pore distribution at around $60 \mathrm{~A}^{\circ}$. Catalytic activity was studied towards liquid-phase oxidation of benzene.
\end{abstract}

Keywords- Mixed rare earth oxide, Ceria-zirconia, BET, TEM, benzene oxidation.

\section{Introduction}

In recent years, ceria and ceria containing material have been thoroughly investigated for the three way catalyst (TWC) [1] application and oxidation catalysis (for example, diesel oxidation catalysts, DOC) because of their oxygen storage capacity (OSC) based on the unique redox behaviour between $\mathrm{Ce}^{3+}$ and $\mathrm{Ce}^{4+}$. $[2,3]$

$\mathrm{CeO}_{2}$ is included in materials used in fuel-cell processes [4], in oxygen permeation membrane systems [5], and as catalysts in numerous economically and technologically important industrial processes. The presence of $\mathrm{CeO}_{2}$ promotes various catalytic reactions such as $\mathrm{CO}_{2}$ activation, $\mathrm{CO}$ oxidation, $\mathrm{CO} / \mathrm{NO}$ removal, low-temperature water-gas shift 6reaction, oxidation of different hydrocarbons, wet oxidation processes of organic compounds, the removal of total organic carbon from industrial wastewaters, methane reforming with $\mathrm{CO}_{2}, \mathrm{SO}_{2}$ reduction with $\mathrm{CO}$.

In the 1990s, many studies were committed to $\mathrm{ZrO}_{2}-\mathrm{CeO}_{2}$ oxides, notably to their synthesis and their catalytic properties. [7-9] It is generally known that the incorporation of zirconium into the ceria lattice creates a higher concentration of defects thus improving the $\mathrm{O}^{2-}$ mobility; such mobility would explain the outstanding ability to store and release oxygen. [10] This property allows the oxidation of hydrocarbons and $\mathrm{CO}$ in rich atmospheres.

Phenol, a valuable intermediate for the synthesis of agrochemicals, petrochemicals and plastics has been mainly manufactured by the cumene process. But this multistep reaction generates phenol and acetone in equimolar amounts. Hence the synthesis of phenol by direct hydroxylation of benzene is attractive both economically and energetically. In the past, several catalysts have been examined using a number of oxidants. Benzene oxidation using hydrogen peroxide has been explored by various researchers. [11-13] Transition metal catalysts have also been demonstrated by researchers for the reaction in presence of comparatively costly oxygen as the oxidant, and a reducing agent. [14, 15] Furthermore, benzene is considered as a priority pollutant by the Environmental Protection Agency. Catalytic oxidation is considered as most promising method for its effective removal.

In the present work, we report the synthesis of ceria zirconia mixed oxides, modification with chromium, their structural characterization using different physico-chemical techniques. Activity of the catalysts towards liquid phase oxidation of benzene is also investigated.

\subsection{Experimental process}

\section{Materials and Methods}

$\mathrm{Ce}(\mathrm{NO} 3) 3.6 \mathrm{H} 2 \mathrm{O}$ and $\mathrm{ZrOCl} 2.8 \mathrm{H} 2 \mathrm{O}$ were dissolved in a vessel with $500 \mathrm{~mL}$ deionized water to obtain a cerium/zirconium mixed solution with a Ce/Zr mole ratio of 1:2. And then it was slowly added to a $500 \mathrm{~mL}$ solution containing cetyl trimethyl ammonium bromide (surfactant/cerium nitrate $=3.4$ molar ratio) under agitation, followed by adding $\mathrm{NH} 4 \mathrm{OH}(28 \mathrm{wt} \%)$ into the mixture, the $\mathrm{pH}$ of the mixture was maintained at around 11. The gel was loaded into a stoppered Teflon bottle and heated hydrothermally at $100^{\circ} \mathrm{C}$ for $48 \mathrm{~h}$. The resultant solid was recovered by filtration, washing and then it was dried in air at $80^{\circ} \mathrm{C}$ for $12 \mathrm{~h}$. Finally, the sample was calcined at $600{ }^{\circ} \mathrm{C}$ for $4 \mathrm{~h}$. It was then impregnated with an aqueous solution of chromium nitrate.

The volume of the aqueous solution of metal used for impregnation depended on the amount of the 
support. The modified ceria-zirconia catalyst was dried at $120^{\circ} \mathrm{C}$ for $2 \mathrm{hrs}$ and then it was calcined at $400^{\circ} \mathrm{C}$ for $4 \mathrm{~h}$. The ceria zirconia support was denoted as $\mathrm{CeZr}$ and chromium modified catalyst as $1 \mathrm{CrCeZr}$ and $2 \mathrm{CrCeZr}$.

\subsection{Characterization}

Nitrogen adsorption measurements were performed at liquid nitrogen temperature with a Micromeritics Tristar 3000 surface area and porosity analyzer. XRD analysis was carried out using Rigaku D-Max Ni filtered $\mathrm{Cu} \mathrm{K} \square$ radiation ( $\lambda=1.5406 \mathrm{~A} 0$ ) diffractometer equipped with diffracted beam monochromator at a scan rate of 50/min analyzer. ICP-AES were done on Thermo electron IRIS INTERPID II XSP DUO model. FT-IR spectra of the prepared samples were measured by the $\mathrm{KBr}$ pellet procedure over the range of 4000-500 cm-1 region using JASCO FTIR spectrometer. Transmission Electron Microscopy was carried out in ultra high resolution analytical electron microscope JEOL 3010. The sample was dispersed in ethanol through sonication and then drop casted on a carbon-coated copper grid. Scanning electron micrographs was taken using JEOL Model JSM6390LV scanning electron microscope with a resolution of $1.38 \mathrm{eV}$. The powdered sample was dusted on a double sided carbon tape, placed on a metal stub and was coated with a layer of gold to minimize charge effects. Perkin Elmer TG analyzer instrument was used for carrying out thermo gravimetric studies. UV-VIS DR spectra were taken in the range 200-800nm on Labomed UV-VIS double beam UVD-500 spectrophotometer equipped with an integrating sphere assembly with a charged coupled device detector, using $\mathrm{BaSO} 4$ as reflectance standard. Temperature-programmed desorption study of $\mathrm{CO} 2$ was carried out in Micromeritics Pulse Chemisorb 2705.

\subsection{Catalytic Activity}

The liquid-phase oxidation of benzene was carried out in a $50 \mathrm{~mL}$ round bottom flask. In a typical reaction, the catalyst powder was suspended in a mixture of acetonitrile $(10 \mathrm{Ml})$ and benzene $(2 \mathrm{~mL})$ and kept in the oil-bath. The oxidant, hydrogen peroxide $\left(\mathrm{H}_{2} \mathrm{O}_{2}\right)$ was added to the system after attaining the reaction temperature. The reaction mixture was stirred using a magnetic stirrer. About $0.5 \mathrm{~mL}$ of solution was withdrawn at regular intervals and analyzed on Chemito 8610 GC equipped with FID detector and an OV-17 packed column. The products obtained were identified by comparison with standard ones. The catalytic activity was expressed as the percentage conversion (wt\%) of benzene and the selectivity for a product is expressed as the amount of the particular product divided by total amount of products multiplied by 100 .

\section{Results And Discussions}

The nitrogen sorption isotherms of ceria zirconia mixed oxides (CeZr) are shown in Fig. 1. It can be classified as a type IV isotherm, typical of mesoporous material. The shape of the curve indicates the absence of a narrow pore size distribution as suggested by the lack of the typical step in the adsorption isotherm which is observed with ordered mesoporous structure. According to IUPAC classification, the hysteresis loop is of type $\mathrm{H} 2$ indicating complex mesoporous structure.
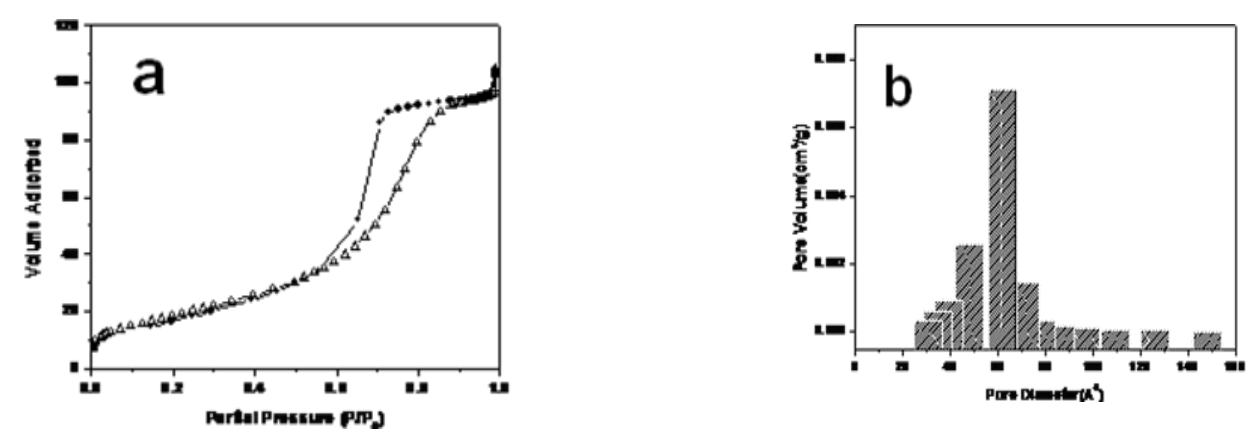

Fig. 1. Nitrogen adsorption-desorption isotherm (a) and Pore size distribution (b) of CeZr.

The uptake at high pressure (P/P0 0.9-1.0) is associated with the void spaces between the particles.[16 ]The presence of uni-modal mesopores are confirmed by the pore size distribution which shows pore distribution covering the range $30-80 \mathrm{~A}^{\circ}$ with a maximum at around $60 \mathrm{~A}^{\circ}$ for mesoporous $\mathrm{CeZr}$ as depicted in Figure 1. Surface area of the ceria zirconia sample was observed to be $70.1 \mathrm{~m} 2 / \mathrm{g}$ and on chromium modification surface area was decreased to $57.9 \mathrm{~m} 2 / \mathrm{g}$. A substantial decrease in BET surface area after impregnation is mainly due to the penetration of the dispersed chromia into the pores of the support.

X-ray diffraction pattern of prepared samples is shown in Fig. 2. Fig 2 shows the XRD patterns of ceria-zirconia. XRD of the prepared material consists of all the peaks corresponding to the cubic fluorite 
structure. The peaks were observed at $2 \theta \sim 29.66,34.12,49.1,58.28$ in comparison with the pure ceria peaks at $2 \theta$ values of $28.78,34.12,47.68$ and 56.48. [17, 18]. High $2 \theta$ values in the pattern reveal the presence of a minor zirconia rich phase. Shift of peaks towards higher $2 \theta$ values is due to the small ionic radius of $\mathrm{Zr}{ }^{4+}$ $\left(0.84 \mathrm{~A}^{0}\right)$ in comparison with that of $\mathrm{Ce}^{4+}\left(0.97 \mathrm{~A}^{0}\right)$. All the diffraction patterns exhibit broad peaks suggesting that as-prepared materials are nanocrystalline materials.

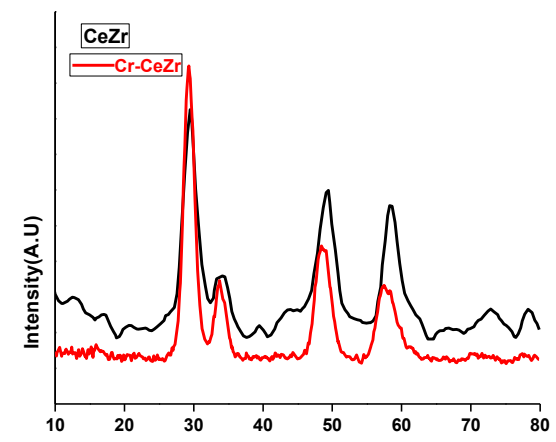

Fig. 2. XRD patterns of $\mathrm{CeZr}$ and $1 \mathrm{CrCeZr}$.

FT-IR spectrum of representative catalysts is displayed in Figure 3. Broad absorption band located in the area from 3200 to $3600 \mathrm{~cm}-1$ corresponds to O-H stretching vibration. The peaks at $1640 \mathrm{~cm}-1$ corresponds to $\mathrm{H}_{2} \mathrm{O}$ bending vibration and at around $1340 \mathrm{~cm}-1$ is due to Ce-OH stretching vibration. Band in the area from 400-700 $\mathrm{cm}-1$ is due to the $\mathrm{CeO}_{2}$ stretching vibration. According to literature data [19] on the vibrational active modes in the fluorite structure, absorption at around $460 \mathrm{~cm}-1$ the main maximum would be assigned to the transverse mode (TO) of the triply degenerated F1u fundamental, and the shoulder to the longitudinal component (LO) of the same fundamental. The IR active mode in the $600-650 \mathrm{~cm}-1$ range is caused by asymmetrically coupled asymmetric $\mathrm{Zr}-\mathrm{O}-\mathrm{Zr}$ stretching, and the mode arising from the symmetric $\mathrm{Zr}-\mathrm{O}-\mathrm{Zr}$ stretching is revealed in the 400-500 cm-1 region. [20]

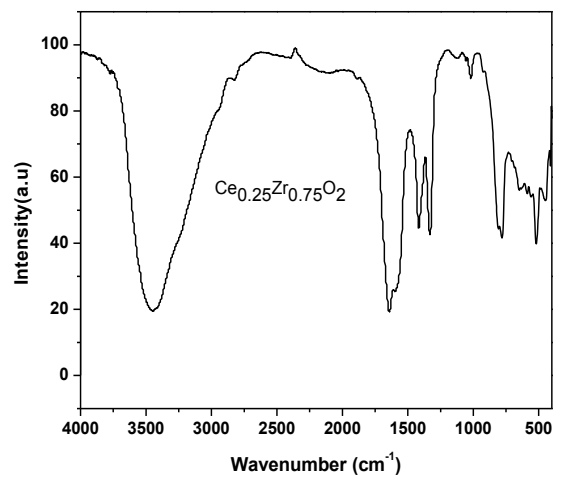

Fig. 3. FT-IR spectrum of CeZr.

The morphology analysis was carried out and is shown in figure 4, 5 and 6. It can be seen from Fig.4 that majority of the ceria crystals consists of aggregated small crystallites of a few nanometres and very homogeneous in size. Sample shows mesoscopic ordering as observed from HRTEM. The lattice fringes of nanocrystalline zirconia can also be well detected by the high resolution TEM image. The selected area electron diffraction (Fig 4d) pattern of the sample exhibited continuous concentric rings, implying that the samples consisted of many very small crystallites with well-defined lattice planes. Average particle size is $12-13 \mathrm{~nm}$ as calculated from particle histogram (Fig 4e). Figure 5 shows the HRTEM and SAED pattern of chromia modified sample. Figure 6 contain scanning electron microscopic pictures of some representative catalysts. After calcination, the particles become irregular shaped and larger sized due to the collapse in structure after heat treatment. 

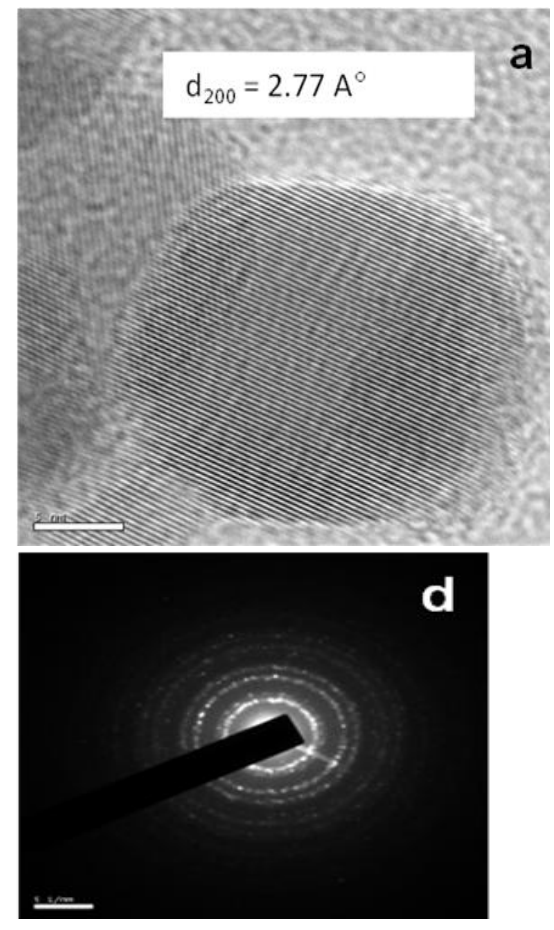
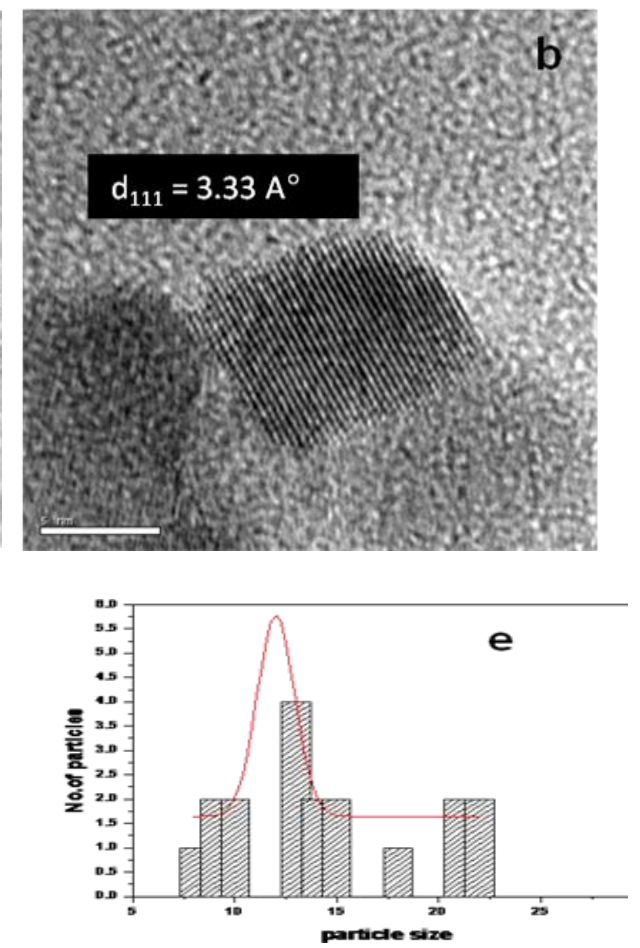

Fig. 4. HR-TEM, SAED pattern (d) and particle size histogram (e) of CeZr.
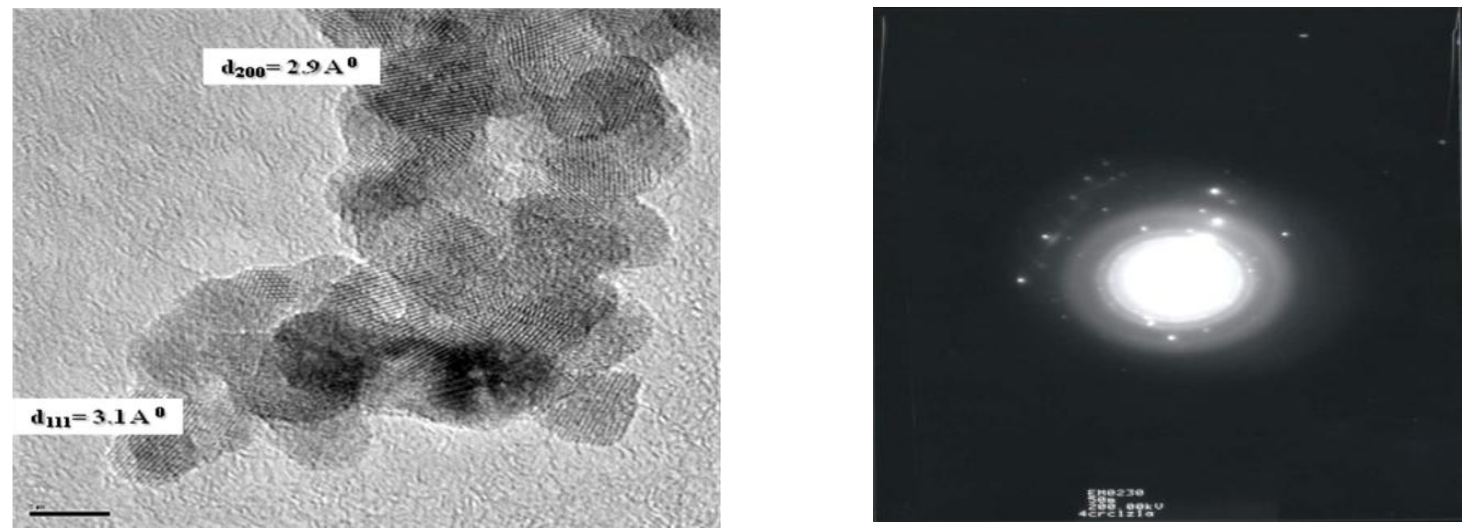

Fig. 5. HR-TEM, SAED pattern of $2 \mathrm{CrCeZr}$.

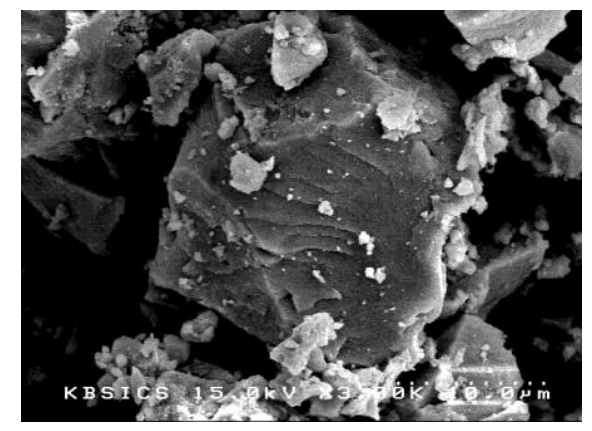

Fig. 6. SEM image of CeZr. 
Thermogram corresponding to $\mathrm{Ce}-\mathrm{Zr}$ mixed oxide shows weight loss at $206{ }^{\circ} \mathrm{C}$ which is attributed to the removal of structural hydroxyl group(Fig 7). A small weight loss at $311^{\circ} \mathrm{C}$ may be due to the removal of surfactant. Weight loss at around $440^{\circ} \mathrm{C}$ can be due to the transition from amorphous into crystalline form.

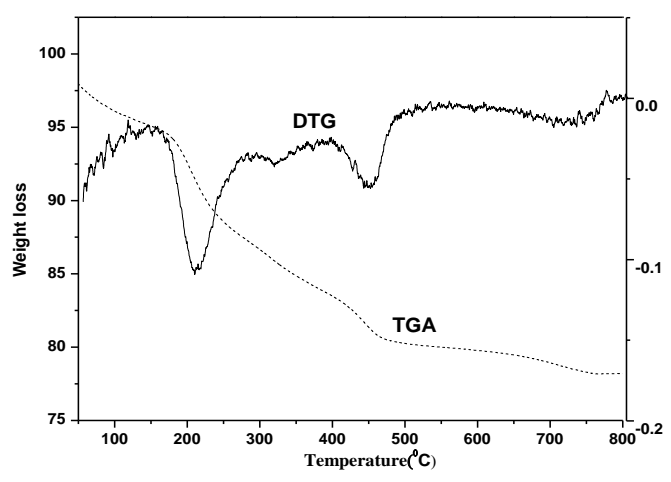

Fig.7. TG-DTA analysis of CeZr.

The spectra, in general, are broad and exhibited a myriad of poorly resolved peaks. Broad absorption bands are observed in the range of 200-350 nm (Fig 8). These bands are attributed to localized O-Ce charge transfer transitions involving a number of surface $\mathrm{Ce} 4+$ ions with different coordination numbers 21 . Interband and $02--$ $\mathrm{Zr} 4+$ transitions of substituted fluorite lattice 22 occur prominently around 340nm.

TPD spectrum of $\mathrm{CO}_{2}$ obtained after $\mathrm{CO}_{2}$ adsorption is shown in Fig.9. Two desorption peaks appear at $199^{\circ} \mathrm{C}$ and $369^{\circ} \mathrm{C}$. It is clear that there are two kinds of $\mathrm{CO}_{2}$ adsorption sites on $\mathrm{CeO}_{2}-\mathrm{ZrO}_{2}$ surface indicating two kinds of basic sites on the surface of the catalyst. The peak at lower temperature may be assigned to a monodentate carbonate interacting with $\mathrm{CeO}_{2}-\mathrm{ZrO}_{2}$. The desorption peak at a higher temperature may be assigned to a bidentate carbonate. The latter species being bonded to the oxide surface by two lattice oxygen ions should exhibit a higher thermal stability than the former ones. [23, 24]

Fig. 8. DR UV-vis spectra of CeZr.

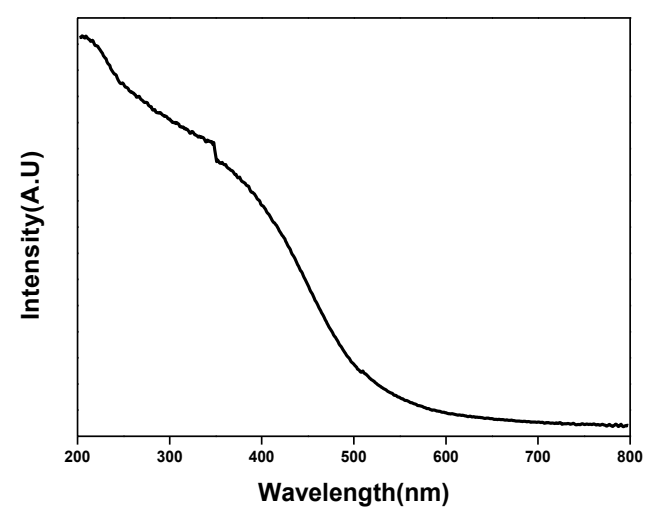

Fig.9. TPD $-\mathrm{CO}_{2}$ after $\mathrm{CO}_{2}$ adsorption on $\mathrm{CeZr}$

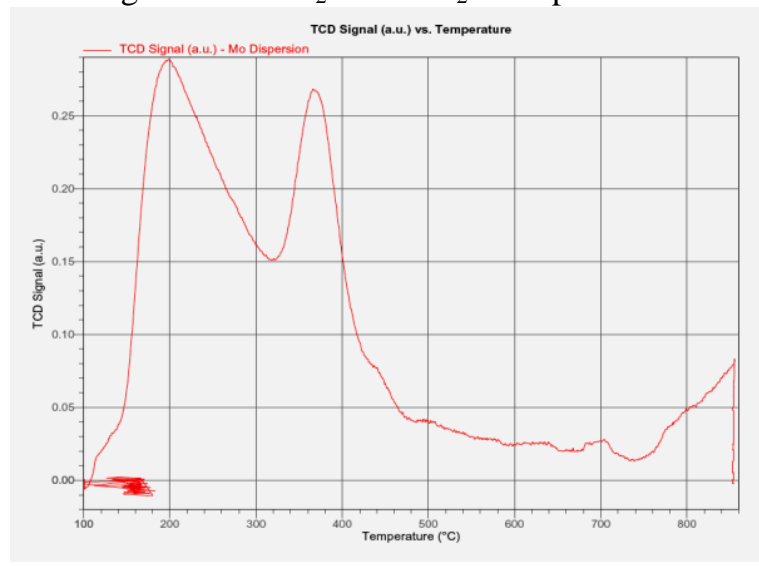

\section{Catalytic activity: Oxidation of benzene}

The catalysts prepared were used in a one-step liquid-phase oxidation of benzene with $\mathrm{H} 2 \mathrm{O} 2$ as the oxidant and acetonitrile as the solvent.

The effect of temperature on the oxidation of benzene was studied by performing the reaction at three different temperatures over chromia modified ceria zirconia with other parameters kept constant and the results are shown in Fig.10. The best results were obtained at $60{ }^{\circ} \mathrm{C}$. When the reaction temperature rose up to $343 \mathrm{~K}$, a sharp increase in the oxidation activity $(51 \%)$ and phenol selectivity $(85 \%)$ was observed. Further increase of temperature decreased the activity as well as phenol yield. This may arise due to the phenol being further oxidized to hydroquinone and 1,4-benzoquinone at the higher temperature. Vaporization of benzene can also occur at this temperature which can result in the decreased activity. [25] 


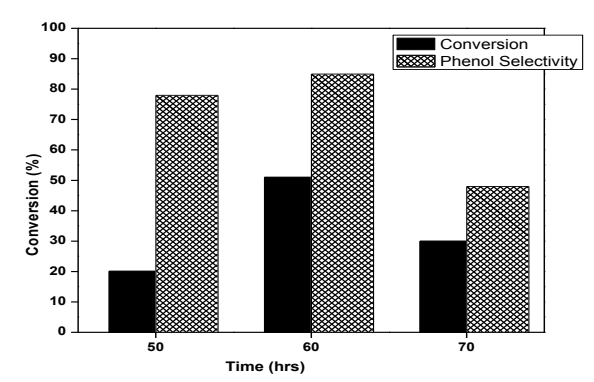

Fig. 10. The effect of temperature on benzene oxidation with $\mathrm{Cr}-\mathrm{CeZr}$ as the catalyst

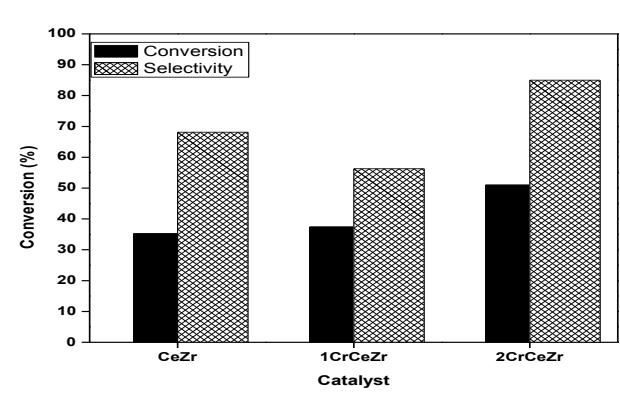

Fig. 11. The oxidation of benzene over catalyst with different metal loading.

(Catalyst mass $=100 \mathrm{mg}$, Benzene: $\mathrm{H}_{2} \mathrm{O}_{2}=1: 2$ ratio (vol); acetonitrile $=10 \mathrm{ml}$ and reaction time $=5 \mathrm{~h}$ ).

Benzene was oxidized using catalyst with different metal loadings under the optimum reaction conditions at 60 ${ }^{0} \mathrm{C}$ (Fig 11). When the amount of chromium increased, the benzene conversion is increased. So the oxidation rate directly depends on the metal content.

For the oxidation of aromatics with hydrogen peroxide over modified metal oxides, it has been proposed that the hydroxylation of the aromatic ring occurs via the heterolytic mechanism, involving the formation of a metalloperoxide species [26-30]. We have not carried out any mechanistic studies in the present work, it is tentatively suggested that a heterolytic cleavage of hydrogen peroxide proceeds via the formation of metallo peroxide. Similar observations have been noticed in literature over metal oxide dispersed analogues [31, 32].

\section{Conclusions}

Nanocrystalline powders of ceria zirconia mixed oxides were successfully synthesized using CTAB as surfactant via hydrothermal method. The technique used here is simple and cost effective. The X-ray diffraction (XRD) analysis suggests that as-prepared materials are nanocrystalline materials. The nitrogen adsorption/desorption isotherm can be classified as a type IV isotherm and hysteresis loop is of type $\mathrm{H} 2$ indicating complex mesoporous structure. Pore size distribution which shows pore distribution covering the range 30-80 $\mathrm{A}^{\circ}$ with a maximum at around $60 \mathrm{~A}^{\circ}$. HRTEM investigation reveals the existence of several nano crystallites with well defined lattice planes. Average particle size is $12-13 \mathrm{~nm}$ as calculated from particle histogram. A single step oxidation of benzene to phenol under mild reaction conditions was carried out successfully over supported ceria zirconia mixed oxide as catalysts with $\mathrm{H}_{2} \mathrm{O}_{2}$. Incorporation of chromia exhibited a promoting effect towards the oxidation reaction. The obtained results suggest the scope of tailoring reaction engineering design for better utilization of this system.

\section{Acknowledgement}

We would like to thank Indian Rare Earths Ltd. for the funding which was used to support this work.

\section{References}

[1] H.-W Jen, G.W Graham, W Chun, R.W McCabe, J.-P Cuif, S.E Deutsch, O Touret. (1999). Characterization of model automotive exhaust catalysts: Pd on ceria and ceria-zirconia supports. Catalysis Today, 50: 309-328.

[2] T. Ozaki, T. Masui, K. Machida, G. Adachi, T. Sakata, H. Mori.( 2000). Redox behavior of surface-modified CeO2-ZrO2 catalysts by chemical filing process. Chem. Mater., 12: 643-649.

[3] Matina Thammachart, Vissanu Meeyoo, Thirasak Risksomboon, Somchai Osuwan.( 2001). Catalytic activity of CeO2-ZrO2 mixed oxide catalysts prepared via sol-gel technique: CO oxidation. Catalysis Today, 68: 53-61.

[4] Jianbing Huang, Lizhai Yang, Ruifeng Gao, Zongqiang Mao, Cheng Wang. (2006). A high-performance ceramic fuel cell with samarium doped ceria-carbonate composite electrolyte at low temperatures. Electrochemistry Communications, 8: $785-789$.

[5] Hitoshi Takamura, Masayuki Ogawa, Koichi Suehiro, Hiroo Takahashi, Masuo Okada.(2008). Fabrication and characteristics of planar-type methane reformer using ceria-based oxygen permeable membrane. Solid State Ionics, 179: 1354-1359.

[6] Zhong-Yong Yuana, Vasko Idakiev, Aurelien Vantomme, Tatyana Tabakova, Tie-Zhen Ren, Bao-Lian Su. (2008). Mesoporous and nanostructured $\mathrm{CeO} 2$ as supports of nano-sized gold catalysts for low-temperature water-gas shift reaction. Catalysis Today, 131:203-210.

[7] Thammachart M, Meeyo V, Risksomboon T and Osuwann S 2001 Catal. Today 6853

[8] Cabana A, Darr J A, Lester E and Poliakoff M 2001 J. Mater. Chem. 11561

[9] Rohart E, Larcher O, H'edouin C, Allain M and Macaudiere P 2001 SAE Int. Paper vol 1, p 1274

[10] Fornasiero P, di Monte R, Rao G, Kaspar J, Meriani S, Trovarelli A and Graziani J 1995 J. Catal. 151168 
[11] Tang Y, Zhang J (2006) Trans Metal Chem 31:299

[12] Park SE, Yoo JW, Lee WJ (1999) In: Proceedings of the 12th IZC, vol 2. Baltimore, USA, p 1253

[13] Monfared HH, Amouei Z (2004) J Mol Catal A Chem 217:161

[14] Kunai A, Wani T, Uehara Y, Iwasaki F, Kuroda Y, Ito S, Sasaki K (1990) Catal Lett 4:139

[15] Fleszer B, Sobkowiak A, Sanecki P (1976) Roez Chem 50:271

[16] Sourav Khan. (2011). Synthesis and characterization of mesoporous ceria-zirconia solid solution. M.Tech Dissertation, Department of chemical engineering, Indian institute of technology- madras.

[17] S. Damyanova, B. Pawelec, K. Arishtirova, M.V. Martinez Huerta, J.L.G. Fierro.( 2008). Study of the surface and redox properties of ceria-zirconia oxides. Applied Catalysis A: General, 337:86-96.

[18] S Damyanova, C.A Perez, M Schmal, J.M.C Bueno. (2002). Characterization of ceria-coated alumina carrier. Applied Catalysis A: General, 234:271-282.

[19] Enrique Fernandez Lopez, Vicente Sanchez Escribano, Marta Panizza, Maria M. Carnasciali and Guido Busca.( 2001). Vibrational and electronic spectroscopic properties of zirconia powders. Journal of Materials Chemistry, 11: 1891-1897.

[20] V.S. Escribano, E.F. Lopez, M. Panizza, C. Resini, J.M.G. Amores, G. Busca, Solid State Sci. 5 (2003) 1369

[21] A. Bensalem, F. Bozon-Verduraz, M. Delamar, G. Bugli.( 1995). Preparation and characterization of highly dispersed silicasupported ceria. Applied Catalysis A: General. 121: 81-93.

[22] Roberta Brayner, Dragos Ciuparu, Gilberto M da Cruz, Francoise Fievet-Vincent, Francois Bozon-Verduraz . (2000). Preparation and characterization of high surface area niobia, ceria-niobia and ceria-zirconia. Catalysis Today, 57: 261-266.

[23] Luis G. Tejuca, Alexis T. Bell, Jose Luis G. Fierro and Juan M. D. Tascon. (1987). Temperature-programmed desorption study of the interactions of $\mathrm{H} 2, \mathrm{CO}$ and CO2 with LaMnO3. Journal of the Chemical Society, Faraday Transactions 1, 83: 3149-3159.

[24] Terrence J. Udovic, J.A. Dumesic.( 1984). Adsorptive properties of magnetite surfaces as studied by temperature-programmed desorption: Studies of O2, NO, CO2, and CO adsorption. Journal of Catalysis, 89:314-326.

[25] K.M. Parida, D. Rath, Structural properties and catalytic oxidation of benzene to phenol over CuO-impregnated mesoporous silica, Appl. Catal. A 321 (2007) 101-108

[26] Notari B (1988) Stud Surf Sci Catal 37:413

[27] Huybrechts DRC, Buskens PL, Jacobs PA (1992) J Mol Catal 71:129

[28] Reddy JS, Sivasanker S, Ratnasamy P (1992) J Mol Catal 71:373

[29] Neumann R, Elad ML (1995) Appl Catal A Gen 122:85

[30] Parvulescu VI, Dumitriu D, Poncelet G (1999) J Mol Catal A Chem 140:91

[31] Monfared HH, Amouei Z (2004) J Mol Catal A Chem 217:161

[32] Ito S, Okuno T, Matsushima H, Tokii T, Nishida Y (1996) J Chem Soc Dalton Trans 4479 